\title{
PRODUCT DEVELOPMENT OF THE LEATHER GOOD USING WALTON'S
} MATRIX

\author{
ALINA IOVAN DRAGOMIR, ALEXANDRA LUCA \\ "Gheorghe Asachi" Technical University of Iasi, Faculty of Industrial Design and Business \\ Management, 28 D. Mangeron, Iasi, Romania, adragomir@tex.tuiasi.ro, \\ alexandra.luca@tuiasi.ro
}

\begin{abstract}
One of the most popular activities included in creative industries in Romania is leather goods craft. Nowadays the consumer needs are very high that's why the companies are facing many challenges and will resist on the market only those who will be the first to launch a certain product or surprise the market. In this paper was used Walton's matrix in order to identify a product that will provide a high profit and is useful for developing production strategies and the long-term development plan of the company's portfolio. This method was applied on a leather good product for women, made from leather. The opinions of the customers about the product, as well as the problems identified by them are very important for the development team in order to obtain new improved products. Modular matrix helps to obtain a technological design model from the design phase. The main advantage of the matrix is the fact that the development is focused on the module without having an impact on the relationships with the other parts. The modular matrix was developed using DSMMatrix program.
\end{abstract}

Keywords: leather goods, Walton matrix, product development

\section{THEORETICAL ASPECTS}

One of the most popular activities included in creative industries in Romania is leather goods craft.

The leather goods market has grown steadily worldwide, because the demand for various products has increased and also consumer needs. In this context, the companies are facing many challenges and will resist on the market only those who will be the first to launch a certain product or surprise the market. As the launch of an absolutely new product is very difficult, the most realistic market strategy remains to surprise the consumer by proposing a well-known product that has an element of novelty. In order to achieve this, an analysis of the company's product portfolio is proposed, and each product is distributed in one of Walton's matrix boxes (Walton, 2008), depending on the market share of each and the growth potential of the market.

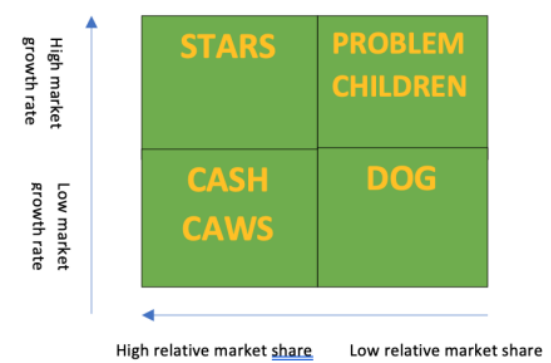

Figure 1. Walton's matrix (adapted of Walton G., 2008) 
The products in the Star category requires a high level of investment but are the products that bring the highest profit. If the market growth potential decreases, these products will fall into the Cash Cows category and investments will be lower.

The products in the Problem Children category have a small market share but operates in a growing market. Products in this category consume a lot of resources but the profit made is insignificant. This product can be passed to Cash Cows or Dogs.

The products in the Cash Cows category have a large market share, so they are wellknown products that do not require new investment. At the same time, it addresses a saturated market segment with low growth potential.

The Dogs category includes those products that also have a reduced market share but also address to a market segment without growth potential. It is a difficult task to move these products to another category.

Despite some shortcomings, the major advantages of the portfolio matrix are that: it helps to identify a product that will provide a high profit and is useful for developing production strategies and the long-term development plan of the company's portfolio.

\section{PRACTICAL ASPECTS}

\section{Applying the Method in Case of Developing a New Leather Goods Product}

An example of applying this method is starting from a product positioned in Walton's portfolio matrix in the Dog box. This products from the company's portfolio have low relative market share and low growth rate.

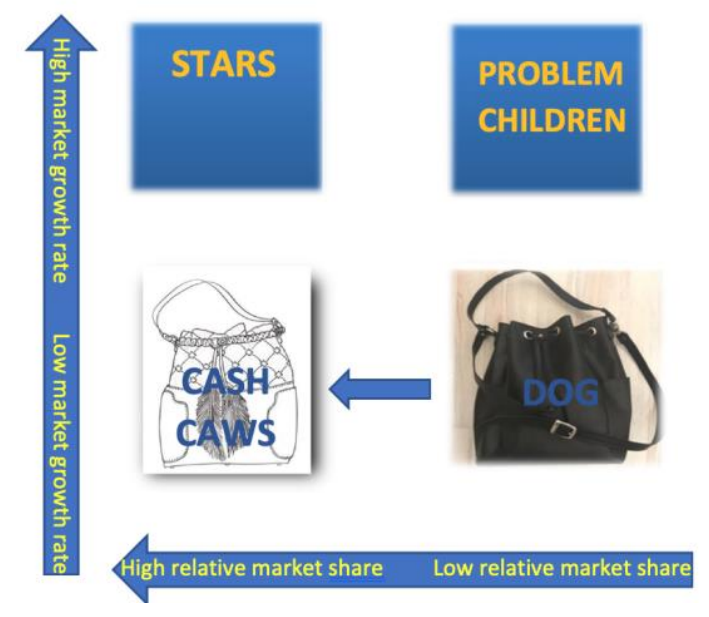

Figure 2. Walton's matrix for the studied product

The aim is to move the product to another box in the matrix. The most profitable solution, because it does not require very large investments, is to move to Cash cows, the product remains on a market with low growth potential but will satisfy as many consumer requirements as possible, so that will have a high relative market share.

The leather good product under analysis is a women's bag, bucket style, made from natural leather, and the product body is divided in the front, back and bottom. The 
product has two outer pockets, without locking system, with an adjustable shoulder strap and a smaller strap. The product closes by tightening a lace.

The opinions of the clients about this product, as well as the problems identified by them are very important for the development team. The most important consumer requirements, retained by the product development team are:

- large space

- many compartments

- hidden anti-theft pocket

- handsfree

- modern look, fresh.

The directions for development and improvement are established as follows:

-adding incorporeal attributes -modification and / or addition of

(concept, product names) decorative elements

-adding functional elements -repositioning on another niche

-dimensional change

To give the product a modern look, the concept chosen for the collection is ALEGRIA, inspired from the show with the same name, by Cirque Du Soleil. Alegria represents a struggle to preserve the power and energy of youth, with a decadent baroque aesthetic, in a nostalgic atmosphere and with a chromatic palette in warm, bright colors. Each product of the collection will have a name such as: joy, happiness.

\section{Functional Diversification}

For this purpose, a modular analysis of the initial product was made. For all the component parts, the relations and connections between them were established. The study implies a detailed knowledge of the technological elements of manufacturing process of the product. Table 1 presents the components of the model and the relationships between them.

Table 1. The components of the model and the relationships between them

\begin{tabular}{|c|c|c|c|c|c|}
\hline ID & Part name & Relationship & Part name & Relationship & ID \\
\hline 1 & Bottom & 2,3 & Side pocket & $14,11,12$ & 13 \\
\hline 2 & Front & $1,3,4,5,9,6,24$ & Piping & $11,12,13$ & 14 \\
\hline 3 & Back & $1,2,4,5,6,9,24$ & $\begin{array}{l}\text { Welt pocket } \\
\text { (bound) }\end{array}$ & $10,17,16$ & 15 \\
\hline 4 & $\begin{array}{l}\text { Right side } \\
\text { outer pocket }\end{array}$ & 2,3 & Bound pocket & $15,17,10$ & 16 \\
\hline 5 & $\begin{array}{l}\text { Left side } \\
\text { outer pocket }\end{array}$ & 2,3 & Zipper & $10,16,15$ & 17 \\
\hline 6 & Staple & $2,3,9,7$ & Handle & 22,24 & 18 \\
\hline 7 & Lace & 6,8 & $\begin{array}{l}\text { Adjustable small } \\
\text { strap }\end{array}$ & 23,21 & 19 \\
\hline 8 & Stopper & 7 & $\begin{array}{l}\text { Adjustable large } \\
\text { strap }\end{array}$ & 23,21 & 20 \\
\hline 9 & Lining Trim & $2,3,10,11,12,6$ & Buckle & 19,20 & 21 \\
\hline 10 & $\begin{array}{l}\text { Back side } \\
\text { lining }\end{array}$ & $11,12,9,15,16,17$ & Ring & 18,24 & 22 \\
\hline 11 & $\begin{array}{l}\text { Right front } \\
\text { side lining }\end{array}$ & $9,10,12,14,13$ & Hardware & 19,20 & 23 \\
\hline 12 & $\begin{array}{l}\text { Left front } \\
\text { side lining }\end{array}$ & $9,10,11,13,14$ & Tab & $2,3,22,18$ & 24 \\
\hline
\end{tabular}

https://doi.org/10.24264/icams-2020.V.4 
Based on the relationships established between the landmarks, a matrix (figure 3) is elaborated where the black dots highlight the connections between the elements.

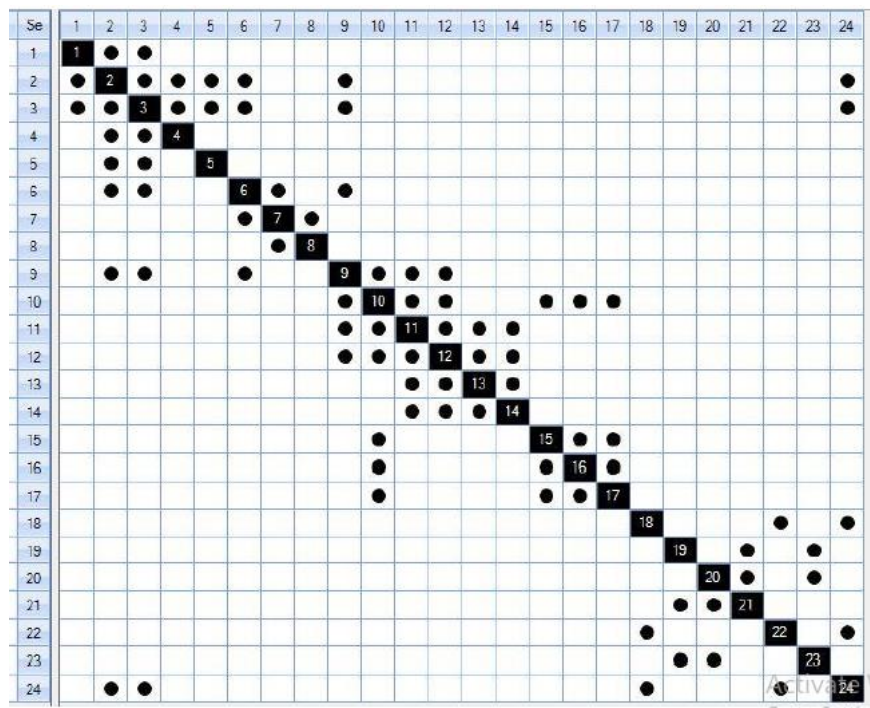

Figure 3. Initial matrix for Bucket basic model

To transform the initial structural matrix from the previous figure, the DSMMatrix program was used, thus obtaining a rearrangement of the rows, so that the dots corresponding to the relationships between the elements are grouped as close as possible to the diagonal. Therefore, a technological design model is obtained from the design stage of the product.

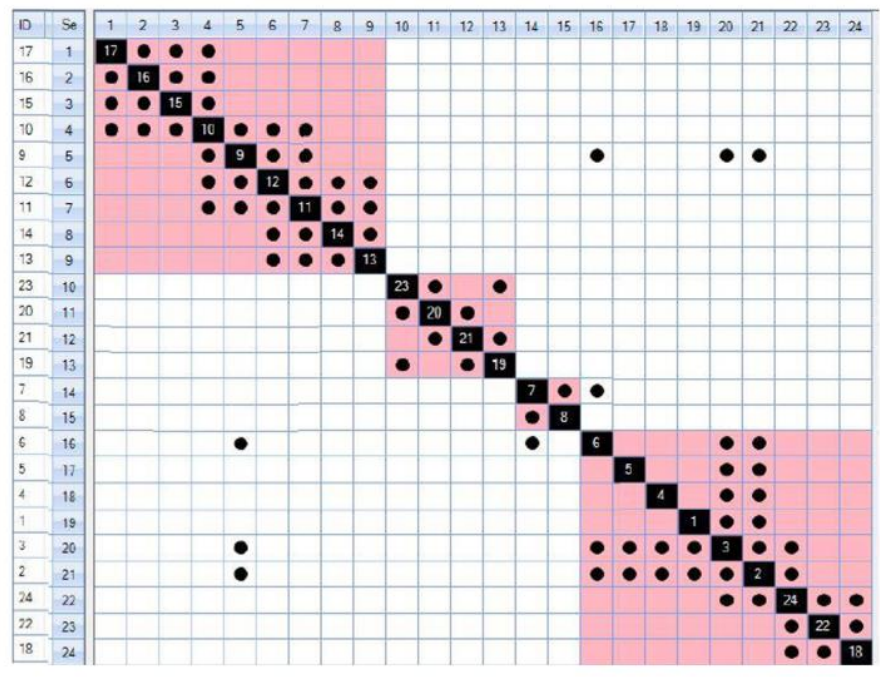

Figure 4. Modular matrix for Bucket basic model 
By segmenting and arranging the initial matrix, 4 modules are obtained (figure 4 ):

Module 1: inner subassembly, lining

Module 2: support system

Module 3: lace with stopper

Module 4: body (front, back, bottom)

All 4 modules are useful in the diversification and improvement phase. In order to obtain a collection, modifications can be made on 1,2 or all the modules or combinations between them.

For exemplification, 2 modules were chosen, respectively 1 and 4, which were distributed on the lines and columns of a matrix. At the intersection of each line with each column resulted in a new variant of the initial model.

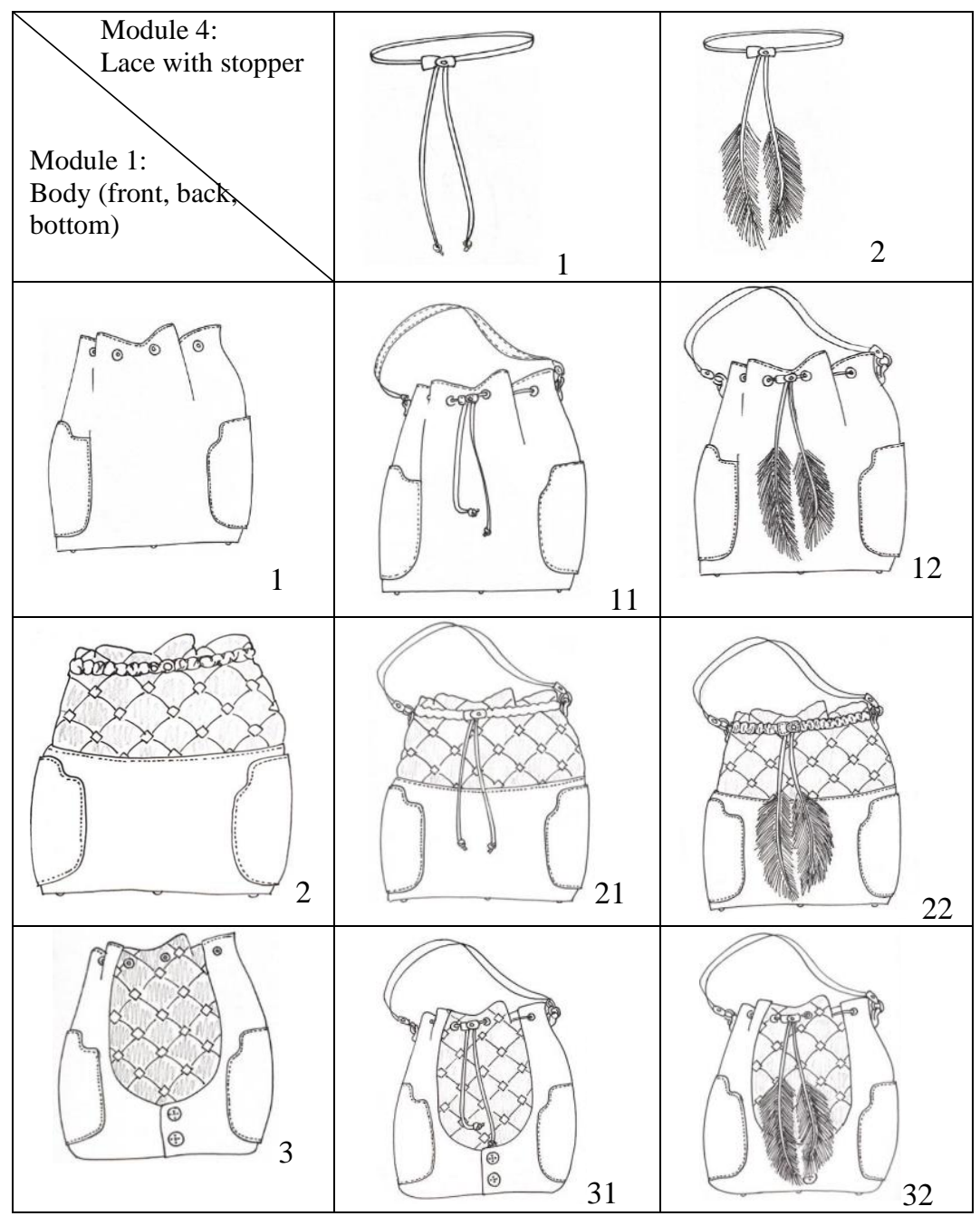

Figure 5. The matrix of the Bucket bag family models 
Figure 5 presents the Bucket bag family obtaining 6 different models with the same functionality without significant changes in the technological and manufacturing process.

\section{CONCLUSIONS}

Walton's matrix is a useful instrument for managing the product portfolio of a company. Also, it helps to decide which product can be maintained, removed or improved. This involve all the departments and the development strategy of the company.

Modular matrix helps to obtain a technological design model from the design phase. The main advantage of the matrix is the fact that the development is focused on the module without having an impact on the relationships with the other parts.

The product development includes 2 components: functional and esthetic. For the analyzed product it was presented the functional development. Development stage should be complete with an esthetic analyze included the chromatic pallet trends according to Lineapelle (International Leather Fair).

\section{Acknowledgements}

This work has been carried out as part of a Master programme (Product Development of Footwear and Leather Goods) at Faculty of Industrial Design and Business Management, Iasi, Romania. Acknowledgements are also due to Yolanda Blazquez Lopez.

\section{REFERENCES}

Gurbuz, E. (2018), “Theory of new product development and its application”, in: Sonyel Oflazoglu (ed.), Marketing, https://doi.org/10.5772/intechopen.74527.

Harnagea, F. (2000), Structure and technology of leather goods (in Romanian), Ed. Cermi, Iași.

Mihai, A. and Pastina, M. (2009), Methods used in conceptualization and development of footwear (in Romanian), Ed. Performantica, Iasi.

Walton, G. (2008), "Theory research and practice in library management 2: The balanced product portfolio", Library Management, 28(4/5), 262-268, https://doi.org/10.1108/01435120710744218. 